\title{
Article
}

\section{Fostering intrinsic motivation in remote undergraduate histopathology education}

\author{
Uraiby, Hussein, Grafton-Clarke, Ciaran, Gordon, Morris, Sereno, \\ Marco, Powell, Barbara and McCarthy, Mark \\ Available at https://clok.uclan.ac.uk/39186/ \\ Uraiby, Hussein, Grafton-Clarke, Ciaran, Gordon, Morris orcid iconORCID: \\ 0000-0002-1216-5158, Sereno, Marco, Powell, Barbara and McCarthy, Mark \\ (2021) Fostering intrinsic motivation in remote undergraduate histopathology \\ education. Journal of Clinical Pathology . ISSN 0021-9746
}

It is advisable to refer to the publisher's version if you intend to cite from the work. http://dx.doi.org/10.1136/jclinpath-2021-207640

For more information about UCLan's research in this area go to http://www.uclan.ac.uk/researchgroups/ and search for <name of research Group>.

For information about Research generally at UCLan please go to http://www.uclan.ac.uk/research/

All outputs in CLoK are protected by Intellectual Property Rights law, including Copyright law. Copyright, IPR and Moral Rights for the works on this site are retained by the individual authors and/or other copyright owners. Terms and conditions for use of this material are defined in the policies page.

\section{CLoK}

Central Lancashire online Knowledge www.clok.uclan.ac.uk

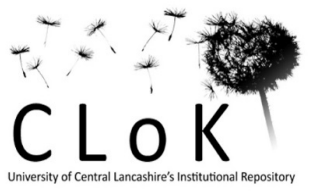




\section{Fostering intrinsic motivation in remote undergraduate histopathology education}

Hussein Uraiby ${ }^{1,2}$, Ciaran Grafton-Clarke ${ }^{1,2}$, Morris Gordon ${ }^{3}$, Marco Sereno ${ }^{4}$, Barbara Powell ${ }^{2}$, Mark McCarthy ${ }^{1,2}$

\footnotetext{
${ }^{1}$ University Hospitals of Leicester NHS Trust, United Kingdom

${ }^{2}$ Leicester Medical School, University of Leicester, United Kingdom

${ }^{3}$ University of Central Lancashire, United Kingdom

${ }^{4}$ Department of Respiratory Sciences, University of Leicester, United Kingdom
}

Word count: 3203

Correspondence should be addressed to Hussein Uraiby, Department of Clinical Education, University Hospitals of Leicester NHS Trust, Leicester Royal Infirmary, Infirmary Square, Leicester, LE1 5WW. Email: hussein_uraiby@hotmail.co.uk 


\section{Abstract}

Aims

The levels of abstraction, vast vocabulary and high cognitive load present significant challenges in undergraduate histopathology education. Self-determination theory describes three psychological needs which promote intrinsic motivation. This paper describes, evaluates and justifies a remotely conducted, post-COVID histopathology placement designed to foster intrinsic motivation.

\section{Methods}

90 fourth-year medical students took part in combined synchronous and asynchronous remote placements integrating virtual microscopy into complete patient narratives through Google Classroom, culminating in remote, simulated multidisciplinary team meeting sessions allowing participants to vote on 'red flag' signs and symptoms, investigations, histological diagnoses, staging and management of simulated virtual patients. The placement was designed to foster autonomy, competence and relatedness, generating authenticity, transdisciplinary integration and clinical relevance. A post-positivistic evaluation was undertaken with a validated pre- and post-placement questionnaire capturing quantitative and qualitative data.

\section{Results}

There was a significant $(\mathrm{p}<0.001)$ improvement in interest, confidence and competence in histopathology. Clinical integration and relevance, access to interactive resources and collaborative learning promoted engagement and sustainability post-COVID. Barriers to online engagement included participant lack of confidence and self-awareness in front of peers.

\section{Conclusions}

Fostering autonomy, competence and relatedness in post-COVID, remote educational designs can promote intrinsic motivation and authentic educational experiences. Ensuring transdisciplinary clinical integration, the appropriate use of novel technology and a focus on patient narratives can underpin the relevance of undergraduate histopathology education. The presentation of normal and diseased tissue in this way can serve as an important mode for the acquisition and application of clinically relevant knowledge expected of graduates.

Keywords: Medical Informatics Computing, Education, Medical, TELEPATHOLOGY 


\section{INTRODUCTION}

The challenges for educators and learners in undergraduate histopathology education are well documented. Students struggle with the vast new terminology, the levels of abstraction, the insufficient time devoted to histopathology teaching and the lack of easily accessible resources. ${ }^{1}$ Graduating doctors consequently report a worrying lack of understanding in histopathology, which is a source of deterrence for doctors pursuing a career in this field. ${ }^{2}$ There are concerns for the ever-dwindling international histopathology workforce. ${ }^{3,4}$ As such, a move away from simple memorisation towards integration and application is suggested to enhance undergraduate interest in histopathology. ${ }^{5}$

Digital resources in histopathology education have been evolving over the last two decades. ${ }^{6}$ Virtual microscopy presents an advantageous platform to present high-quality resources which can be accessed remotely and is transforming pathology education. ${ }^{7}$ The COVID-19 pandemic has accelerated the need to digitise resources. ${ }^{8,9}$

Digital systems facilitating remote access to learning resources are important; ${ }^{10}$ however, the theoretical underpinnings guiding the use of digital resources are critical in maximising the utility and relevance of the resources and guiding how educators can best use them. This is particularly key to consider in post-COVID pivots to online learning as achieving such clinical integration will involve a complex interplay of direct pedagogy associated with the primary methods of learning, as well as the added complexity of remote digital solutions.

The COVID-19 pandemic has necessitated a revolution, rather than evolution, of pivots to remote and online education. ${ }^{11}$ As such, important issues relating to the manner in which digital pathology resources are integrated into educational designs must be addressed to maintain excellent post-COVID pathology education. 
This study describes, evaluates, and justifies a novel placement in histopathology for undergraduate UK medical students that contains virtual microscopy, integrating digital pathology resources into complete patient narratives and simulated multidisciplinary team meetings (MDTs), fostering intrinsic motivation through considerations of autonomy, competence and relatedness.

\section{Aim}

1) To design and deploy a theoretically underpinned, remote, clinically integrated histopathology placement.

2) To evaluate this educational design in terms of Kirkpatrick hierarchy levels 1 and 2.

\section{METHODS}

\section{Theoretical underpinning}

Effective learning requires a motivation to learn. This motivation may be extrinsic, driven by forces such as reward or punishment, or intrinsic, driven by interest, enjoyment and curiosity. Intrinsic motivation is associated with higher achievement rates than extrinsic motivation. ${ }^{12}$ It is facilitated through a process of internalisation, where external self-regulations can transform into internalised habits and motives, generating a feeling of autonomous self-regulation and value.

Self-determination theory (SDT) describes how addressing three psychological needs can promote internalisation and, consequently, intrinsic motivation. ${ }^{13}$ The design of this placement was constructed to foster these three psychological needs (Figure 1).

\section{[Insert Figure 1 near here]}

Autonomy refers to the need to be one's own origin or source of behaviour. This was enabled through flexible, remote access to digital resources and the power for a group of learners to 
determine the progression of simulated, virtual clinical cases. Competence refers to the need to feel effective in whatever actions one pursues and performs. This was generated through the application of knowledge in establishing complete patient histories, interpreting investigations and determining progressively complex histological diagnoses. Relatedness refers to the need to feel connected with others, to have a sense of belonging with others and a community. ${ }^{14}$ The collaborative nature of the asynchronous activities and the synchronous simulated MDT session permitted social interactions, discussions and votes, bringing students together with peers and tutors to share and develop ideas.

Allowing autonomy in the interpretation of investigations, histology and management planning permitted clinical authenticity, thereby generating a replication of genuine clinical practice and promotion of professional values. ${ }^{15}$

\section{Transdisciplinary, integrated clinical learning}

Integrated learning, in the context of this placement, refers to the organisation of education in a way that traverses subject matter lines and allows for the assimilation of various aspects of the curriculum into meaningful associations, steeped in genuine, patient-centred clinical practice. ${ }^{16}$ This places histopathology into relevant and important clinical context, reflecting the specialty's fundamental clinical importance and shifts away from isolated histopathology education.

\section{Asynchronous learning activities}

Groups of 12-15 students joined the Google Classroom virtual learning environment. Table 1 describes the structure of activities within this environment, with corresponding references to the key elements of self-determination theory: competence, autonomy, and relatedness. 


\begin{tabular}{|c|c|c|c|c|}
\hline Education Activity & Description & Competence & Autonomy & Relatedness \\
\hline $\begin{array}{l}\text { Eliciting a history } \\
\text { (asynchronous) }\end{array}$ & $\begin{array}{l}\text { Students were provided with a clinical vignette, based } \\
\text { upon common real-life } \\
\text { scenarios. Students worked collaboratively to 'ask questions' to } \\
\text { a virtual patient. Students were then provided with a complete } \\
\text { medical history in response to the questions asked. }\end{array}$ & $\begin{array}{l}\text { In responding to the questions asked, } \\
\text { student would feel a sense of } \\
\text { effectiveness in their ability } \\
\text { to perform the task. The sense } \\
\text { of volition. }\end{array}$ & $\begin{array}{l}\text { Students were free } \\
\text { to choose any questions they felt } \\
\text { were relevant and appropriate to } \\
\text { ask. Seeking student input } \\
\text { conveys empathy. Student } \\
\text { contribution is encouraged rather } \\
\text { than mandated (minimisation of } \\
\text { controlling words). }\end{array}$ & $\begin{array}{l}\text { Collaborative approach to history } \\
\text { taking encouraged development of } \\
\text { teamwork. Direct and non- } \\
\text { judgemental } \\
\text { communication between peers and } \\
\text { facilitators. }\end{array}$ \\
\hline $\begin{array}{l}\text { Requesting } \\
\text { investigations } \\
(\text { asynchronous) }\end{array}$ & $\begin{array}{l}\text { Students then offered their suggestions on the required } \\
\text { investigations. Only investigations which were clinically } \\
\text { appropriate were 'accepted'. If an important investigation was } \\
\text { not requested by a student, then the results of this investigation } \\
\text { were not provided. If a requested investigation was not } \\
\text { clinically appropriate, then the student requesting the } \\
\text { investigation were asked to explain the reasoning for the } \\
\text { request. }\end{array}$ & $\begin{array}{l}\text { In suggesting an appropriate request, } \\
\text { students would feel a sense of } \\
\text { accomplishment that } \\
\text { their contribution has led to } \\
\text { progression of the 'patient } \\
\text { journey'. Encouragement } \\
\text { of reflective practice to develop } \\
\text { expertise. }\end{array}$ & $\begin{array}{l}\text { Students were free to request any } \\
\text { investigation they felt were } \\
\text { appropriate. Encouraged to } \\
\text { justify investigations and determine } \\
\text { clinical relevance / appropriateness } \\
\text { of the investigatory approach. }\end{array}$ & $\begin{array}{l}\text { Shifting the focus from the } \\
\text { perspective of the } \\
\text { facilitator (provider) to the } \\
\text { student (receiver) of the feedback. }\end{array}$ \\
\hline $\begin{array}{l}\text { Differential diagnoses } \\
\text { (asynchronous) }\end{array}$ & $\begin{array}{l}\text { Students report on abnormalities in the investigations and } \\
\text { present a differential diagnosis based on the questions asked } \\
\text { (history) and investigations requested (if appropriate). }\end{array}$ & $\begin{array}{l}\text { Self-monitoring of } \\
\text { knowledge within the context of a } \\
\text { virtual 'real-life' clinical } \\
\text { case. Difficulty pitched at an } \\
\text { appropriate level to avoid } \\
\text { undermining a sense of competence. }\end{array}$ & $\begin{array}{l}\text { Autonomy is facilitated through the } \\
\text { use of encouraging questions and } \\
\text { providing meaningful } \\
\text { satisfactory answers. }\end{array}$ & $\begin{array}{l}\text { Feedback provided was non- } \\
\text { judgemental and kind, allowing } \\
\text { students to build a self- image of } \\
\text { strengths and weaknesses. }\end{array}$ \\
\hline $\begin{array}{l}\text { Exploration of virtual } \\
\text { histology } \\
\text { (asynchronous) }\end{array}$ & $\begin{array}{l}\text { Students remotely explore fully annotated virtual histology } \\
\text { from "patient", guiding their interpretation and compare the } \\
\text { images with normal virtual histology. }\end{array}$ & $\begin{array}{l}\text { Application of previously acquired } \\
\text { histology and pathology knowledge to } \\
\text { a clinical case }\end{array}$ & $\begin{array}{l}\text { Flexible, remote access to digital } \\
\text { pathology platform. Curiosity- } \\
\text { based exploration of annotated } \\
\text { virtual histology. }\end{array}$ & $\begin{array}{l}\text { The group all have access to the same } \\
\text { images, building a sense of } \\
\text { collaboration and community. }\end{array}$ \\
\hline $\begin{array}{l}\text { Simulated MDT } \\
\text { (synchronous) }\end{array}$ & $\begin{array}{l}\text { Facilitated by a tutor, the group adopt the roles of a } \\
\text { multidisciplinary team and discuss and vote on "red flag" } \\
\text { symptoms, further investigations, how to obtain tissue, } \\
\text { histological diagnoses, staging and further } \\
\text { management. Students follow a similar process for two new, } \\
\text { unseen patients. The session ends with feedback based on the } \\
\text { actual histological diagnoses and how patients with those } \\
\text { diagnoses are normally investigated and managed, including } \\
\text { reference to immunohistochemistry and personalised cancer } \\
\text { therapy. }\end{array}$ & $\begin{array}{l}\text { Students engage in self-monitoring } \\
\text { of their capabilities in the subject } \\
\text { matter and obtain feedback on their } \\
\text { competence by peers and the } \\
\text { facilitators. Growing sense } \\
\text { of mastery. } \\
\text { Through the asynchronous learning } \\
\text { tasks, culminating in the simulated } \\
\text { MDT, there is a sense of } \\
\text { student contribution to patient } \\
\text { care and a perception of self- } \\
\text { progression. }\end{array}$ & $\begin{array}{l}\text { The significance of entrusting } \\
\text { professional activities upon the } \\
\text { learners. The session was delivered } \\
\text { with no pressure (no assessment) and } \\
\text { no judgement. } \\
\text { Students had a 'voice' which shapes } \\
\text { the discussion and outcome. }\end{array}$ & $\begin{array}{l}\text { Collaboration within a peer- } \\
\text { group within a fun, stimulating, and } \\
\text { dynamic learning environment. } \\
\text { Increasing sense of community } \\
\text { between learners and professional } \\
\text { community. Working within a peer- } \\
\text { group where the focus is shifted from } \\
\text { the individual to the context. }\end{array}$ \\
\hline
\end{tabular}

Table 1: Synchronous and asynchronous activities undertaken throughout the placement and their underpinning in self-determination theory 
Students were given a presenting complaint and directed to ask questions to elicit a complete history in the comments sections. They were then prompted to request investigations, which invariably included obtaining tissue for histological assessment. Students were instructed that investigations needed to be clinically relevant, and inappropriate investigations would be rejected, further reflecting genuine clinical practice and creating authenticity. Students were given the investigations they requested, including access to a digital pathology platform that contained annotated normal tissue and tissue from the patient. They were then prompted to determine the abnormalities and suggest an initial management plan. The total learning time students spent on this asynchronous component of the placement was 4 - 6 hours. During this asynchronous stage, the facilitator acted as the virtual simulated patient and was provided with exhaustive potential answers in response to questions posed by the students during the history taking tasks. The facilitator was also provided with multiple clinically relevant investigations and was directed to post the investigations that the students requested onto Google Classroom (see supplementary material appendix 1 for screenshots from the Google Classroom and appendix 2 for a detailed flowchart of activities).

\section{Synchronous learning activity}

The culminating session within this placement was a synchronous, remote, simulated multidisciplinary team meeting, where each student adopted the role of a core member of the MDT (e.g., secondary care physician, radiologist, surgeon, oncologist and histopathologist), facilitating a related, transdisciplinary, authentic learning experience.

During the simulated MDT session, the facilitator reviewed the cases and, using the comments from Google Classroom, prompted discussions and conducted online voting relating to the 'red flag' signs and symptoms exhibited by the virtual patients, the abnormalities identified in the investigations, the histological diagnoses, staging and grading of malignancies, as well as 
management plans. The patient narratives were designed to change depending upon the votes of students, again permitting learner autonomy in controlling the simulated patients' clinical outcomes.

New, unseen cases were introduced in the MDT session to facilitate the transfer of newly acquired skills to more challenging clinical situations, further establishing competence of the learners. Each complete session was undertaken twice per group, exploring benign and malignant respiratory and dermatology patient narratives.

\section{Context}

Participants were fourth-year medical students on a five-year undergraduate UK medical school curriculum undertaking a rotation in 'Cancer Care'. During this rotation, students normally attend outpatient cancer and palliative care clinics, join inpatient oncology and haematology ward rounds, attend a local hospice and receive didactic teaching on common cancer presentations and investigations. There was no histopathology input into this rotation prior to the described intervention. Fourth year students were selected as they had accrued a degree of clinical experience, having completed two six-month rotations in general medicine and general surgery. Students had previously received one isolated module on pathology during their first year, which introduced broad pathological processes including inflammation and neoplasia. They had also encountered histology during their first year when learning about anatomy. These first-year modules were didactic, occasionally incorporating static histology images, but not light nor virtual microscopy. After this, students had not received any dedicated teaching relating to pathology or histology and students had not received any clinically integrated histopathology education at all.

109 students took part in these placements; this number represents all fourth-year students who have so far rotated through the hospital during the academic year 2020-2021 through COVID 
restrictions who consented to take part. Students undertook rotations in groups of approximately 30 . To reduce the ratio of students to facilitators and improve the likelihood of active participation, ${ }^{17}$ two groups of 12-15 students were created for each session with one tutor per group.

Ethical approval was sought and granted for this work by the University Ethics Sub-Committee for Medicine and Biological Sciences (reference: 22459-hu15-ls:medicine - see supplementary material appendix 3 for ethical approval letter).

\section{Resources}

Google Classroom was used as the hub for the dissemination of information and tasks. This is free to use with a Gmail account.

Slide were scanned with a Hamamatsu NanoZoomer S210 digital slide scanner. Philips Xplore was used as the remotely accessible platform for asynchronous and synchronous virtual slide viewing, annotating and sharing. Other free digital pathology websites are available, which would offer similar learning opportunities, notably the Leeds Virtual Pathology website (https://www.virtualpathology.leeds.ac.uk/).

The creation of the clinical cases, virtual slide sets and material for Google Classroom took 120 hours. Once materials were created, facilitators spent around one hour per placement responding to the asynchronous components of the course and two to three hours delivering the synchronous simulated MDT session.

Blackboard Collaborate was the online platform for the remote, simulated MDT meeting. Interaction was facilitated through webcams and microphones and screen-share features were used to review the virtual histology. The integrated polling function was used for group voting. 
Full learning resources and evaluative tools have been published, and freely available for reuse. $^{18}$

\section{Additional pedagogical underpinnings}

Virtual microscopy significantly reduces the extraneous cognitive load of the learning event. ${ }^{19}$ By presenting high-quality histology in a remotely accessible and easy-to-use format, the nonessential tasks of the learning event are minimised, in stark contrast to traditional methods of histology teaching such as light microscopy or static images which present significant physical and psychological barriers to effective education. ${ }^{20}$ Virtual histology images were annotated in keeping with the Multimedia Learning Theory principles; ${ }^{21}$ annotations automatically directed users to the relevant area of the image, at a magnification that best depicted the structure or process that was annotated. This acknowledges the limited capacity an individual has to process visual information. Annotations permitted a temporary removal of the irrelevant visual stimuli, of which there may be many in a histological image, allowing users to actively process, organise and construct relevant knowledge effectively.

\section{Evaluation}

A post-positivist research design was employed for this study, ${ }^{22}$ utilising survey methodology to obtain quantitative and qualitative data. An anonymous, matched, 13-item questionnaire was completed before and after the placement (see supplementary material Appendix 4 for full question schedules). The questionnaires were designed to determine the impact of the placement on attitudes and confidence (Kirkpatrick level 1) and technical knowledge (Kirkpatrick level 2). ${ }^{23}$ Students were asked three clinically applied histopathology-focused single best answer questions pre-placement and post-placement, which were created by the authors and reviewed by three consultant histopathologists. The wording of the questions was 
altered following their input. These questions progressively increased in difficulty and related to description, identification and application of knowledge. The solutions to the questions were not discussed or reviewed at any point during the placement. The construct validity and clarity of the question schedule was refined by a panel of ten consultant histopathologists, who are all involved in undergraduate and postgraduate education. The questionnaire was piloted with 15 fourth-year medical students to ensure clarity and relevance of items. ${ }^{24}$ These participants were not included in the final results. Statistical analysis was performed independently by a medical data analyst. Pre- and post-placement differences were analysed using McNemar's test (for the knowledge-based questions) and Wilcoxon matched-pairs signed-rank test (for the attitudes and confidence Likert-scaled questions). A thematic analysis of qualitative data was undertaken. Free-text responses were repeatedly read and coded; patterns that emerged were named and a thematic map constructed to determine inter-relation. ${ }^{25}$ A free-text question relating to contribution in Google Classroom was created to investigate reasons for compliance or non-compliance with instructions and tasks.

\section{RESULTS}

109 students took part in these clerkships. 90 participants completed both pre- and postplacement questionnaires. Results are presented in Table 2. 
Table 2: Change in interest, confidence, and knowledge, following participation in the course

\begin{tabular}{|c|c|c|c|c|c|}
\hline & Pr & urse & & urse & \\
\hline Question & Median & $\begin{array}{l}\text { Mean } \\
( \pm \text { SD })\end{array}$ & Median & $\begin{array}{l}\text { Mean } \\
( \pm \text { SD })\end{array}$ & $\begin{array}{c}\text { P-value relating to } \\
\text { median }\end{array}$ \\
\hline Interest & & & & & \\
\hline $\begin{array}{l}\text { How interesting do you find } \\
\text { histopathology? }\end{array}$ & 2 & $1.8 \pm 0.5$ & 4 & $3.6 \pm 0.5$ & $<0.001$ \\
\hline Confidence & & & & & \\
\hline $\begin{array}{l}\text { How confident are you identifying } \\
\text { acute inflammatory cells? }\end{array}$ & 1 & $1.6 \pm 0.4$ & 3 & $3.1 \pm 0.6$ & $<0.001$ \\
\hline $\begin{array}{l}\text { How confident are you identifying } \\
\text { chronic inflammatory cells }\end{array}$ & 1 & $1.4 \pm 0.3$ & 3 & $2.6 \pm 0.5$ & $<0.001$ \\
\hline $\begin{array}{l}\text { How confident are you at } \\
\text { identifying blood vessels? }\end{array}$ & 2 & $2.0 \pm 0.5$ & 4 & $3.7 \pm 0.5$ & $<0.001$ \\
\hline $\begin{array}{l}\text { How confident are you at } \\
\text { identifying different types of } \\
\text { epithelium? }\end{array}$ & 2 & $1.8 \pm 0.4$ & 3 & $3.2 \pm 0.5$ & $<0.001$ \\
\hline $\begin{array}{l}\text { How confident are you at } \\
\text { identifying normal glandular } \\
\text { structures }\end{array}$ & 1 & $1.8 \pm 0.4$ & 3 & $3.0 \pm 0.5$ & $<0.001$ \\
\hline $\begin{array}{l}\text { How confident are you identifying } \\
\text { coagulative necrosis }\end{array}$ & 1 & $1.7 \pm 0.5$ & 3 & $3.1 \pm 0.5$ & $<0.001$ \\
\hline $\begin{array}{l}\text { How confident are you } \\
\text { distinguishing the nucleus from the } \\
\text { cytoplasm }\end{array}$ & 3 & $3.0 \pm 0.8$ & 5 & $4.3 \pm 0.5$ & $<0.001$ \\
\hline $\begin{array}{l}\text { How confident are you } \\
\text { distinguishing a benign cell from a } \\
\text { malignant cell? }\end{array}$ & 1 & $1.7 \pm 0.5$ & 4 & $3.5 \pm 0.4$ & $<0.001$ \\
\hline 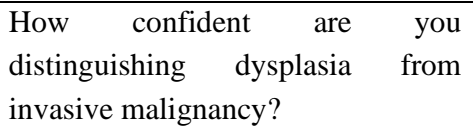 & 1 & $1.4 \pm 0.4$ & 3 & $2.6 \pm 0.5$ & $<0.001$ \\
\hline $\begin{array}{l}\text { How confident are you } \\
\text { distinguishing positive and negative } \\
\text { immunohistochemistry }\end{array}$ & 1 & $1.4 \pm 0.4$ & 3 & $3.2 \pm 0.6$ & $<0.001$ \\
\hline Knowledge & & & & & \\
\hline Knowledge questions (/3) & 1 & $0.9 \pm 0.4$ & 3 & $2.3 \pm 0.5$ & $<0.001$ \\
\hline
\end{tabular}

Analysis conducted using Wilcoxon matched-pairs signed rank test for interest and confidence and McNemar's test for knowledge-based questions.

Note: all values refer to a 5 -point Likert scale $(1=$ not at all, $2=$ slightly, $3=$ moderately, $4=$ quite, 5 = extremely). 
There was a significant improvement in attitude towards histopathology as a speciality; the median response to 'how interesting do you find histopathology?' shifted from a median 5point Likert score of 2 (slightly interested) to 4 (quite interested) $(\mathrm{p}<0.001)$ (Figure 2a and 2b). Similarly, the median response to 'is seeing the microscopic appearance of a disease useful in your understanding of that disease?' rose from 2 (slightly useful) to 4 (quite useful) (p < 0.001). Across the ten questions regarding self-reported confidence in correctly identifying normal and abnormal histological features, there was a significant improvement across all. Students were asked three clinically applied histopathology-focused single best answer questions. The mean number of correct responses increased from $0.9 \pm 0.4$ per student to $2.3 \pm$ 0.5 per student, following completion of the placements $(\mathrm{p}<0.001)$.

\section{[Insert Figure 2 near here]}

The qualitative data revealed that students valued the manner in which histopathology was made relevant to their studies and experiences through its integration beyond distinct disciplines and into clinical context. The staggered release of educational material and flexible, remote access to digital resources gave students a greater sense of autonomy over their learning. Students also reflected that the simulated MDT session served as a forum to discuss questions and topics that arose throughout the placement and that collaborative approaches to learning alleviated pre-existing anxieties relating to the subject material. Interest was also generated by the knowledge that student votes impacted on the progression of the cases (Figure 3).

\section{[Insert Figure 3 near here]}

Contribution to Google Classroom was not mandated and there was generally excellent engagement and contribution from participants and facilitators. The questionnaire demonstrated that barriers to contribution for students was lack of confidence, awareness of peers seeing their responses, another student already posting their intended contribution and missing the deadlines for contribution. 
The placement has been sustainable throughout the pandemic and will continue to be delivered in this manner going forward.

\section{DISCUSSION}

The wide-ranging impacts of the COVID-19 pandemic on medical education are being realised, and the subsequent revolution of educational practice is under way. The question is no longer whether online, remote interventions should be used, but how they can be designed in the most effective way. This study demonstrates a novel application of self-determination theory to underpin a clinical histopathology placement which has significantly increased participant interest, confidence and competence in histopathology.

The 'new normal' of medical education and its embrace of remotely conducted learning events must account for the motivation of learners and the manners in which it can be fostered and maximised. By considering the autonomy, competence and relatedness of remote educational design, the potential to generate intrinsic motivation in learners can be realised and capitalised upon. Previous sources of intrinsic motivation which may have been implicit in pre-COVID clinical learning must be made explicit in the post-COVID educational landscape in order to maintain excellent standards of clinical learning.

This work builds upon previous research that has established technology, ${ }^{26}$ flipped classroom approaches, ${ }^{27}$ and collaborative learning as advantageous in histopathology education, ${ }^{28}$ and presents a sustainable, novel learning event, underpinned by a new understanding of selfdetermination theory which places patient care at its centre, thereby generating interest, engagement, confidence and competence in clinical histopathology. 
Through consideration of autonomy, competence and relatedness, as well as transdisciplinary clinical integration, the authenticity of the educational intervention was maximised. This approach, in contrast to pathology or histology taught as an isolated module, mirrors the reality of clinical working, whereby doctors-in-training navigate the uncertainty and complexity of medicine.$^{29}$ Complete integration of clinical practice into learning ensures that the development of knowledge is relevant, meaningful, immersed in clinical practice, tailored to required outcomes ${ }^{30}$ and amenable to alteration as part of the iterative evolution of lifelong learning. ${ }^{31}$ Integrating histopathology theory and practice in this way allows students to discover the value of the profession, deduce the core characteristics necessary for competence as a pathologist, witness the tangible impacts that histopathology has on patient care and to infuse a sense of meaning and intrigue towards the speciality.

The decision not to include a pass/fail summative assessment in this course was based on the potential barriers that such assessment strategies present to the development of intrinsic motivation and authenticity of learning activities.

Although summative assessments can drive learners to acquire, retain and integrate knowledge, ${ }^{32}$ their associated rewards and sanctions can be detrimental to professional development. Learners may prioritise obtaining the best possible marks through rote memorisation and strategic revision tailored to the criteria of the assessment over a deep learning approach aimed at understanding, assimilating and applying knowledge into future professional practice. ${ }^{33}$ Such learning strategies which permit arrival at a goal by any means are not aligned with self-determination theory as learner autonomy to develop interest, intrigue, academic satisfaction, and therefore intrinsic motivation, may be restricted by the assessment. ${ }^{34}$ 
Furthermore, in order to promote intrinsic motivation, there was a need for learning activities to be clinically authentic. As such, opportunities for discussion and debate, reflective of the genuine discussions held between a multidisciplinary team were designed into the asynchronous and synchronous components of this initiative. These debates often revolved around weighing up multiple reasonable options for patient investigation and management and their advantages and disadvantages, rather than identifying correct answers from incorrect answers. This intentionally reflected the nuanced and dynamic nature of clinical medicine. The need to maintain this clinical authenticity further informed the decision not to include a summative assessment as promoting the identification of an absolute correct answer may have stifled the depth of inquiry required for critical reflection in genuine clinical problem solving.

The strengths of this study lie in the thorough validation of data collection tools, sample size and the repeated use of multiple clinical cases over the academic year. The grounding of this intervention in pedagogical theory has permitted positive outcomes and the foundations to be conducted remotely, under the pressures of COVID-19 and remain sustainable beyond COVID-19. Additionally, this work specifically addresses and minimises risks to underpinning, resource, setting, pedagogical and content bias, ensuring replicability.

Whilst randomising to control groups would have controlled variables further, this was deemed unjust in an innovative educational intervention. Other limitations relate to the use of three single-best answer questions to evaluate Kirkpatrick outcome 2. Although a more extensive assessment would have permitted greater reliability of findings, there was insufficient time allocated to be able to conduct a more thorough assessment. More cases, relating to more benign and malignant conditions would have also permitted further reliability of findings. 


\section{CONCLUSION}

We have demonstrated that an online, remote clinical placement whose design was underpinned by self-determination theory significantly improved participant interest, confidence and competence in histopathology. By creating authentic, clinically integrated learning events which fostered autonomy, competence and relatedness, learners were afforded the opportunity to participate in activities which facilitated the effective acquisition, synthesis and application of knowledge in genuinely recreated clinical contexts. This authenticity, clinical integration and targeted use of digital resources goes some way to mitigating against the threats posed by the vast vocabulary, levels of abstraction and high cognitive load associated with histological interpretation. It provides a new dimension through which normal and diseased tissue can facilitate a comprehensive understanding of illness presentation, investigation and management.

\section{KEY MESSAGES}

- Underpinning remote educational designs with self-determination theory can generate intrinsic motivation to learn.

- This study is designed to foster autonomy, competence and relatedness, and carefully consider the application of digital pathology resources in a transdisciplinary, integrated, authentic manner.

- This has resulted in a significant improvement in undergraduate student interest, confidence and competence in histopathology 


\section{Notes on Contributors}

Hussein Uraiby, MBChB, PGCert, FHEA is a Specialty Trainee in Histopathology and a Clinical Teaching Fellow at the University Hospitals of Leicester NHS Trust, United Kingdom.

Ciaran Grafton-Clarke, MBChB, PGCert, is a Clinical Teaching Fellow at the University Hospitals of Leicester NHS Trust, United Kingdom.

Morris Gordon, MBChB, PhD, MMed, is a Cochrane Coordinating Editor of Cochrane Gut, Chair of the BEME Executive Committee, and a Professor of Evidence Synthesis and Systematic Review, University of Central Lancashire, Preston, UK.

Marco Sereno, MSc is a data manager and analyst at the Department of Respiratory Sciences, University of Leicester, United Kingdom.

Barbara Powell, MBChB, FRCP is a Consultant in Palliative Care at LOROS Hospice, Leicester, undergraduate lead for Cancer Care and head of the 5th year at Leicester Medical School, University of Leicester, United Kingdom.

Mark McCarthy PhD, FRCS is a Consultant Vascular Surgeon, Director of Clinical Education and Associate Clinical Director at the University Hospitals of Leicester NHS Trust and Honorary Associate Professor at Leicester Medical School, University of Leicester, United Kingdom. 


\section{Funding}

This work has not received any funding.

\section{Acknowledgements}

The authors would like to acknowledge Prof. John Le Quesne for his invaluable contributions to this work.

\section{Competing Interests}

The authors declare no competing interests.

\section{Ethics Approval Statement}

Ethical approval was granted by the University Ethics Sub-Committee for Medicine and Biological Sciences. Ethics Reference: 22459-hu15-ls:medicine

\section{Contributorship Statement}

HU lead the conception, design, implementation, evaluation, analysis, write-up and revision of this work.

C-GC contributed to additional write-up, data analysis, review and revision of this work. MG contributed to review of pedagogical underpinning, additional write-up, revision and supervision of this work.

MS contributed to data analysis, additional write-up and review of this work.

BP contributed to implementation and review of this work.

MM contributed to supervision and review of this work. 


\section{References}

1. García M, Victory N, Navarro-Sempere A, Segovia Y. Students' Views on Difficulties in Learning Histology. Anat Sci Educ. 2019;12(5):541-549. doi:10.1002/ase.1838

2. Lempp H, Cochrane M, Seabrook M, Rees J. Impact of educational preparation on medical students in transition from final year to PRHO year: a qualitative evaluation of final-year training following the introduction of a new Year 5 curriculum in a London medical school. Med Teach. 2004;26(3):276-278. doi:10.1080/2480142159042000192046

3. Robboy SJ, Weintraub S, Horvath AE, et al. Pathologist Workforce in the United States: I. Development of a Predictive Model to Examine Factors Influencing Supply. Arch Pathol Lab Med. 2013;137(12):1723-1732. doi:10.5858/arpa.2013-0200-OA

4. Royal College of Pathologists. Workforce Planning Report 2016. Published online 2016. https://www.rcpath.org/asset/CDA0171D-2F0E-4F06-AA809626B741CE5F/ (accessed 3 March 2021)

5. Miller SA, Perrotti W, Silverthorn DU, Dalley AF, Rarey KE. From college to clinic: Reasoning over memorization is key for understanding anatomy. Anat Rec. 2002;269(2):69-80. doi:10.1002/ar.10071

6. King TS, Sharma R, Jackson J, Fiebelkorn KR. Clinical Case-Based Image Portfolios in Medical Histopathology. Anat Sci Educ. 2019;12(2):200-209. doi:10.1002/ase.1794

7. Harris G. Digitisation will transform the future of pathology. Br. J. Health Care Manag. 2020;26(4):1-4. doi:10.12968/bjhc.2020.0018

8. Samueli B, Sror N, Jotkowitz A, Taragin B. Remote pathology education during the COVID-19 era: Crisis converted to opportunity. Ann Diagn Pathol. 2020;49:151612. doi:10.1016/j.anndiagpath.2020.151612

9. Caruso MC. Virtual Microscopy and Other Technologies for Teaching Histology During Covid-19. Anat Sci Educ. 2021;14(1):19-21. doi:10.1002/ase.2038

10. Dee FR. Virtual microscopy in pathology education. Hum Pathol. 2009;40(8):1112-1121. doi:10.1016/j.humpath.2009.04.010

11. Gordon M, Patricio M, Horne L, et al. Developments in medical education in response to the COVID-19 pandemic: A rapid BEME systematic review: BEME Guide No. 63. Med Teach. 2020;42(11):1202-1215. doi:10.1080/0142159X.2020.1807484

12. Vermunt JD. Metacognitive, cognitive and affective aspects of learning styles and strategies: A phenomenographic analysis. High Educ. 1996;31(1):25-50. doi:10.1007/BF00129106

13. Ryan RM, Deci EL. Self-determination theory and the facilitation of intrinsic motivation, social development, and well-being. Am Psychol. 2000;55(1):68-78. doi:10.1037/0003066X.55.1.68 
14. ten Cate OThJ, Kusurkar RA, Williams GC. How self-determination theory can assist our understanding of the teaching and learning processes in medical education. AMEE Guide No. 59. Med Teach. 2011;33(12):961-973. doi:10.3109/0142159X.2011.595435

15. Fredholm A, Manninen K, Hjelmqvist H, Silén C. Authenticity made visible in medical students' experiences of feeling like a doctor. Int J Med Educ. 2019;10:113-121. doi:10.5116/ijme.5cf7.d60c

16. Harden RM. The integration ladder: a tool for curriculum planning and evaluation. Med Educ. 2000;34(7):551-557. doi:10.1046/j.1365-2923.2000.00697.x

17. Steinert Y. Twelve tips for effective small-group teaching in the health professions. Med Teach. 1996;18(3):203-207. doi:10.3109/01421599609034161

18. Grafton-Clarke C, Uraiby H. Educational Clerkship in histopathology: learning resources. Published online 2021. doi:10.7910/DVN/OMQ6RM

19. Young JQ, Van Merrienboer J, Durning S, Ten Cate O. Cognitive Load Theory: Implications for medical education: AMEE Guide No. 86. Med Teach. 2014;36(5):371384. doi:10.3109/0142159X.2014.889290

20. Alotaibi O, ALQahtani D. Measuring dental students' preference: A comparison of light microscopy and virtual microscopy as teaching tools in oral histology and pathology. Saudi Dent J. 2016;28(4):169-173. doi:10.1016/j.sdentj.2015.11.002

21. Mayer RE. Multimedia Learning. Cambridge, UK. Cambridge University Press 2009.

22. Cohen L, Manion L, Morrison K. Research Methods in Education. Abingdon, UK. Routledge 2018.

23. Kirkpatrick JD, Kirkpatrick WK. Kirkpatrick's Four Levels of Training Evaluation. Alexandria, VA. ATD Press 2016.

24. Artino AR, La Rochelle JS, Dezee KJ, Gehlbach H. Developing questionnaires for educational research: AMEE Guide No. 87. Med Teach. 2014;36(6):463-474. doi:10.3109/0142159X.2014.889814

25. Braun V, Clarke V. Using thematic analysis in psychology. Qual Res Psychol. 2006;3(2):77-101. doi:10.1191/1478088706qp063oa

26. Mione S, Valcke M, Cornelissen M. Evaluation of virtual microscopy in medical histology teaching: Virtual Microscopy in Histology Teaching. Anat Sci Educ. 2013;6(5):307-315. doi:10.1002/ase.1353

27. Hew KF, Lo CK. Flipped classroom improves student learning in health professions education: a meta-analysis. BMC Med Educ. 2018;18(1):38. doi:10.1186/s12909-018$1144-\mathrm{z}$

28. Tian Y, Xiao W, Li C, et al. Virtual microscopy system at Chinese medical university: an assisted teaching platform for promoting active learning and problem-solving skills. $B M C$ Med Educ. 2014;14(1):74. doi:10.1186/1472-6920-14-74 
29. Wijnen-Meijer M, ten Cate O, van der Schaaf M, Burgers C, Borleffs J, Harendza S. Vertically integrated medical education and the readiness for practice of graduates. $B M C$ Med Educ. 2015;15(1):229. doi:10.1186/s12909-015-0514-z

30. General Medical Council. Outcomes For Graduates. Published online 2020. https://www.gmc-uk.org/education/standards-guidance-and-curricula/standards-andoutcomes/outcomes-for-graduates (accessed 7 Feb 2021)

31. Atwa HS, Gouda EM. Curriculum Integration in Medical Education: A Theoretical Review. Intel Prop Rights. 2014;2(2). doi:10.4172/2375-4516.1000113

32. Epstein RM. Assessment in Medical Education. Cox M, Irby DM, eds. $N$ Engl J Med. 2007;356(4):387-396

33. Kordestani Moghaddam A, Khankeh HR, Shariati M, Norcini J, Jalili M. Educational impact of assessment on medical students' learning at Tehran University of Medical Sciences: a qualitative study. BMJ Open. 2019;9(7):e031014.

34. Ryan RM, Deci EL. Intrinsic and extrinsic motivation from a self-determination theory perspective: Definitions, theory, practices, and future directions. Contemporary Educational Psychology. 2020;61:101860. 


\section{Autonomy}

Flexible, remote access to learning hub and digital resources

Freedom to choose and justify questions, investigations, diagnoses and managements

Curiosity-based exploration of resources

Absence of pass/fail assessment

\section{Competence}

Application of knowledge to guide authentic clinical decision making

Effectiveness in establishing history and identifying abnormalities

Sense of accomplishment in directing patient journeys

Sense of progress and challenge as clinical cases develop
Relatedness

Groups of 12-15 learners per placement

Collaborative activities - shift from individual to context

Discussion, debate and group voting

Direct, non-judgemental communication

Sense of community

Figure 1: A Venn diagram demonstrating the three psychological needs of self-determination theory which provide the conceptual framework of this educational design

IM - Internal Motivation 
Figure 2a: Pre- and post-course group responses to 'how interesting do you find histopathology?'

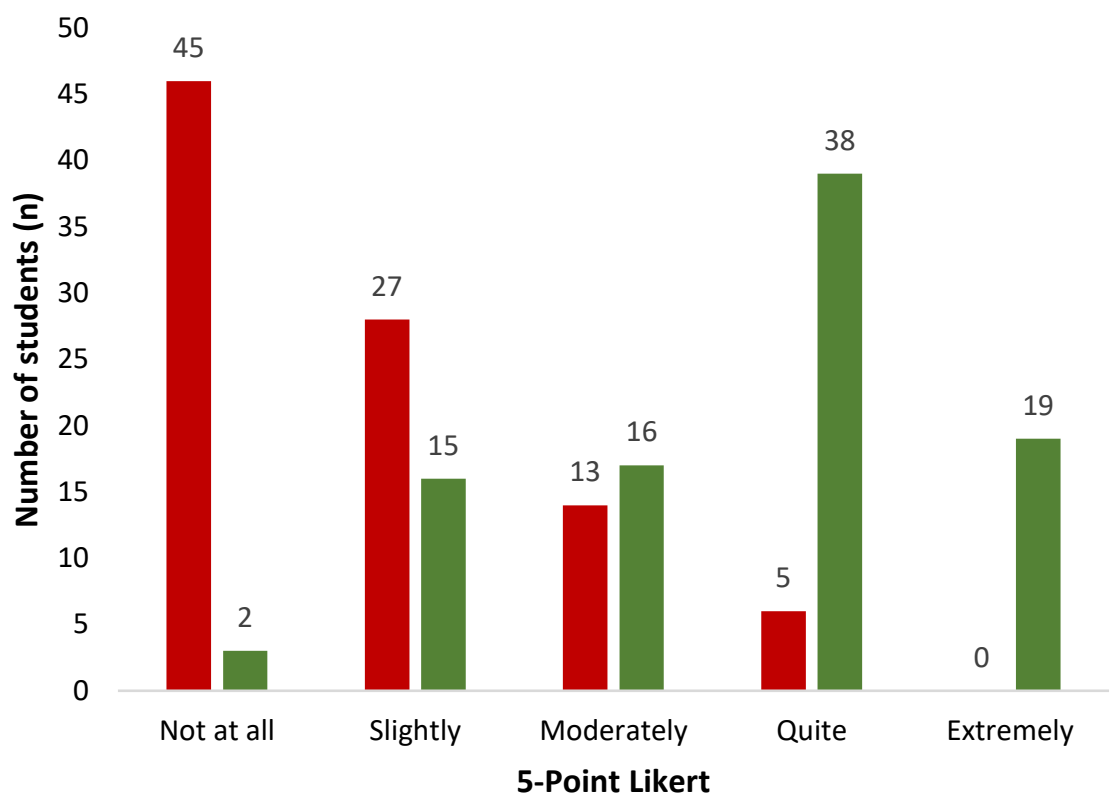

- Pre-Course Post-Course

Figure 2b: Pre- and post-course individual responses to 'how interesting do you find histopathology?'

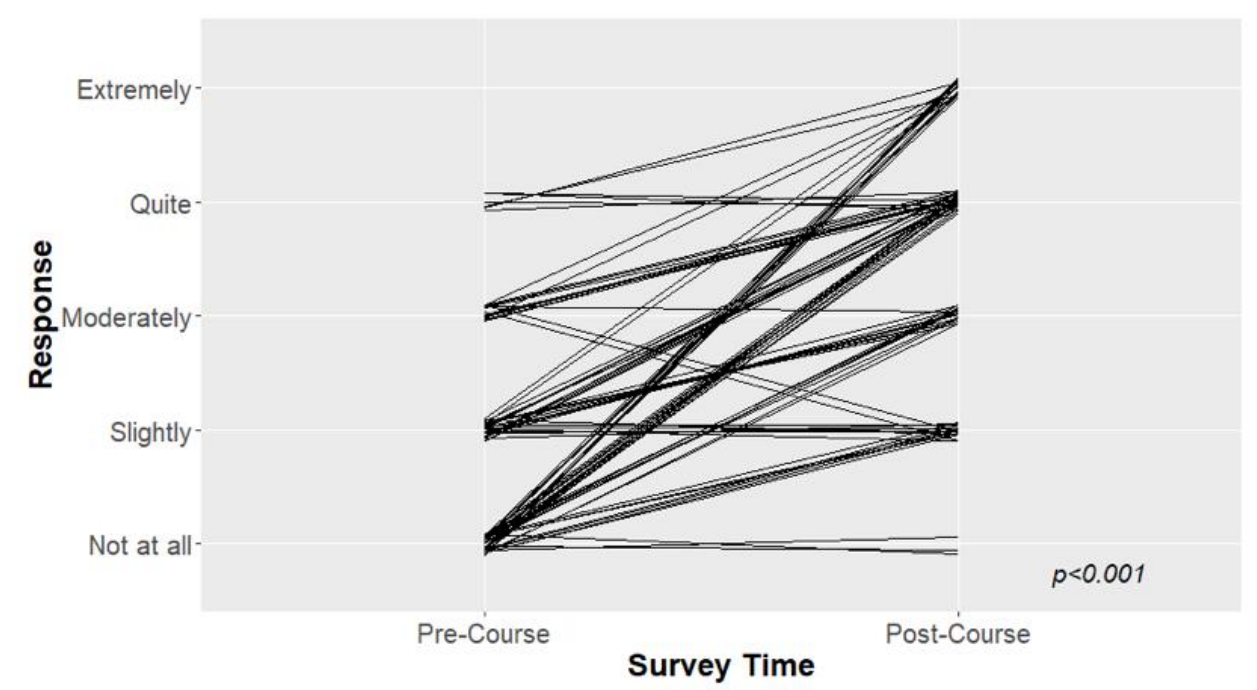


Figure 3: A thematic map of qualitative responses

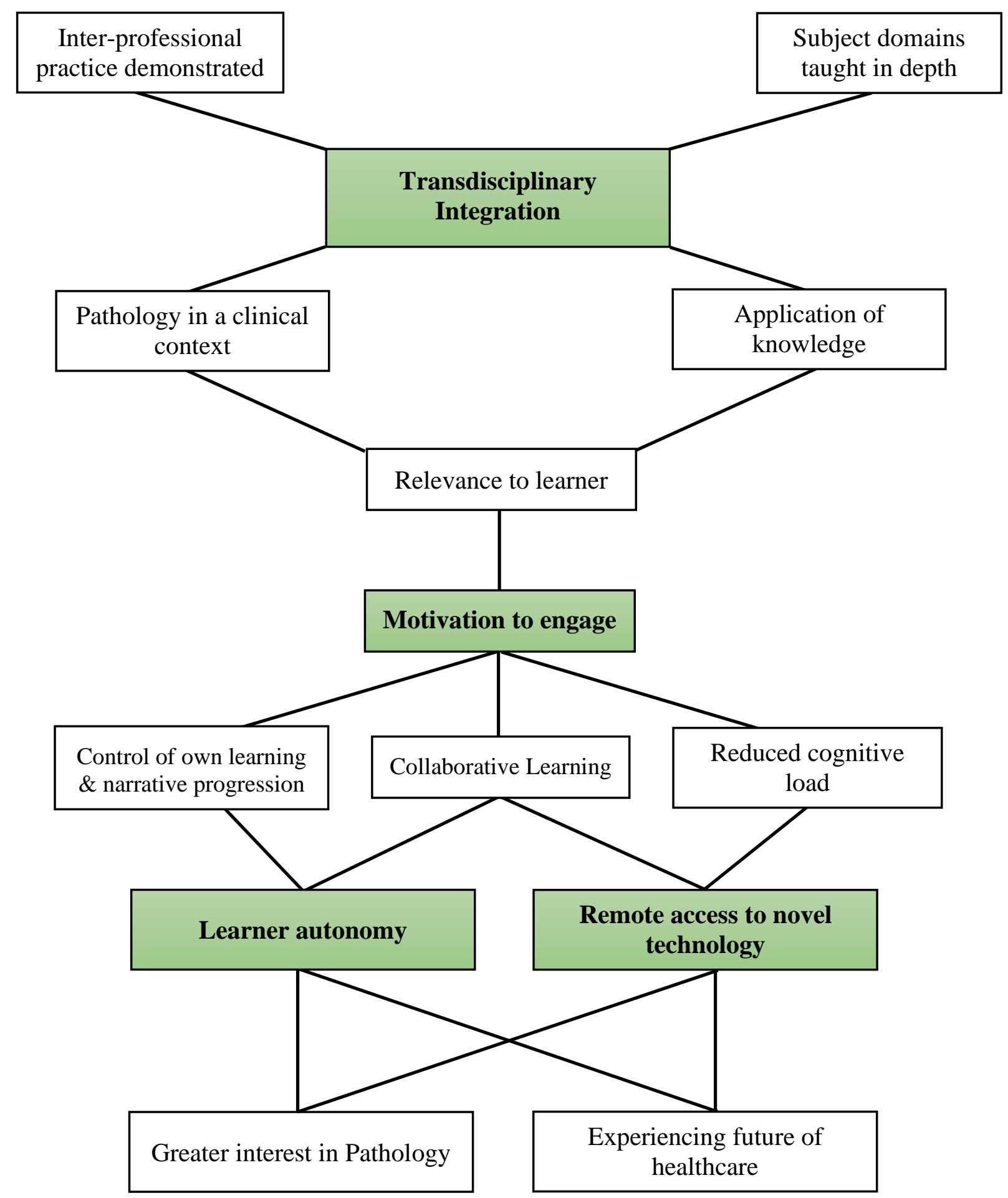

Key 